\title{
A test of the Wagner-Rescorla model's prediction of no response decrement in a nondifferential following a differential schedule of reinforcement
}

\author{
S. E. BRANDON \\ Hofstra University, Hempstead, New York
}

\begin{abstract}
When the pigeons are trained with a multiple variable time (VT) 30-sec VT 60-sec EXT (30-60EXT) schedule with key colors A, B, and C (respectively), response to $A$ is greater than response to $B$, and response to $B$ is greater than response to $C$. When the birds are switched to multiple VT 60-sec VT 60-sec VT 60-sec (60-60-60) with A, B, and C, response to A and $B$ falls to the level previously seen for $\mathrm{C}$. The Wagner-Rescorla model predicts this pattern of results. The model also predicts no decrement in response to $B$ if the switch is to 60-60 training with $A$ and $B$ only (omitting $C$ ). The present experiment showed a severe decrement of keypecking in 60-60 with $A$ and $B$, equivalent to that seen in 60-60-60 with $A, B$, and C. Other explanations of the performance-failure appear necessary. An alternative description of V'T-VT schedules, that they contain no signal for no reward, is considered in terms of the notion that no-reward periods are necessary for the elimination of behaviors that compete with keypecking.
\end{abstract}

Uncorrelated presentations of key lights (CSs) and food (USs) to a pigeon that has been previously trained to peck at the key light will extinguish keypecking (Gamzu \& D. R. Williams, 1973; Lindblom \& Jenkins, 1981; Tomie, 1981). When US presentations in extinction retard the rate of response cessation relative to that rate obtained with CS-alone extinction, as has been demonstrated most powerfully for avoidance and escape responses (Coulson, Coulson, \& Gardner, 1970; Fowler, 1971; Kelleher, Riddle, \& Cook, 1963; McKearney, 1969; Stretch, Orloff, \& Dalrymple, 1968) but also for conditioned suppression (Ayres \& DeCosta, 1971) and leverpressing (Rescorla \& Skucy, 1969) in rats, an explanation in terms of the adventitious temporal contiguity of response and reinforcement (Skinner, 1948) is probably most common. Other investigators have emphasized the discriminative properties of reinforcement (Rescorla \& Skucy, 1969; Uhl, 1973; Zeiler, 1968). However, when US presentations hasten extinction, as has been shown for pigeons in "random CS/US extinction," in which the CS and US are uncorrelated with respect to each other (Tomie, 1981), then clearly the continued presence of the US has some function other than as a discriminative stimulus or adventitious reinforcer of the conditioned response (CR). A different role of the US in such situations also is suggested by the fact that random CS/US extinction (again relative to CS-alone extinction) may retard reacquisition of the CR to that

Requests for reprints should be sent to S. E. Brandon, Department of Psychology, Hofstra University, Hempstead, NY 11550. same CS or to another CS (Tomie, Hayden, \& Biehl, 1980; Tomie, Rhor-Stafford, \& Schwam, 1981). An account of both faster response-elimination and retarded reacquisition was offered by Tomie (1981), who suggested that contextual cues are conditioned when "paired with" the US during the random CS/US phase. The CS is then compounded with the excitatory context and nonreinforced, which results in a faster decrement in CS-associative strength than would occur in the absence of an excitatory context (cf. Wagner, 1969).

An understanding of what processes are responsible for response-cessation when the US is continued in uncorrelated CS/US extinction training is made more difficult by the fact that the comparison between uncorrelated and correlated training is complex: in the switch to uncorrelated CS/US extinction, not only is the CS-US contingency severely reduced (Rescorla, 1968), but contiguity of the CS with the US also becomes extremely rare. If reinforcements in the absence of the CS simply are added to the correlated situation, to produce the uncorrelated state and yet maintain CS-US contiguity, then the greater density of reinforcement itself might be expected to suppress responding (Gibbon, Locurto, \& Terrace, 1975). An unconfounded type of comparison, suggested by B. A. Williams (1976) and demonstrated by Farley (1980) and Brandon (1981), is one in which "correlated" and "uncorrelated" training conditions are equated for CS-US contiguity as well as for density of reinforcement, and CS/US contingency alone is reduced. Here, pigeons are trained with multiple variable time (VT) schedules with three 
components: VT 30-sec VT 60-sec EXT (30-60-EXT), with food presented twice per minute on the average when the key is color $A$, once per minute on the average when the key is color $B$, and not at all when the key is color $\mathbf{C}$. Following acquisition and stable performance with rates of keypecking higher to $\mathbf{A}$ than to $B$ and rates higher to $B$ than to $C$, the procedure is changed to a nondifferential schedule, multiple VT 60-sec VT 60-sec VT 60-sec (60-60-60). Here, food is presented once per minute on the average in the presence of all three key colors, A, B, and C. Keypecking to A and B falls off dramatically, and extinction is accomplished. Although reacquisition following the three-component $60-60-60$ schedule has not yet been compared with that following EXTEXT-EXT, retarded reacquisition of keypecking following two-component VT 30-sec VT 30-sec versus EXT-EXT training has been demonstrated (Brandon, 1981). The VT-VT schedule appears, thus, to be the functional analog of the uncorrelated CS/US procedure and offers as well an unconfounded comparison of performance in "correlated' (differential) and "uncorrelated"' (nondifferential) training.

An interpretation of response-cessation in VT 60sec VT 60-sec VT 60-sec similar to that offered by Tomie (1981) for extinction in random CS/US training, was suggested by Brandon (1981). The analysis used the model of classical conditioning developed by Wagner and Rescorla (1972). As a result of VT 30sec VT 60-sec EXT $(\mathrm{AX}++\mathrm{BX}+\mathrm{CX}-)$ training, $\mathrm{A}$ acquires the majority of available associative strength (V), $V_{B}$ and $V_{X}$ (the associative strength acquired by $B$ and by the context, $X$, respectively) are intermediate, and $V_{C}$ (strength of stimulus $C$ ) is negative. When the VT 60-sec VT 60 -sec VT 60-sec procedure is introduced, there is an increase in $\mathbf{V}_{X}$ as a result of the first $\mathbf{C X}+$ trial. Assuming $\mathbf{V}_{\mathbf{A}}$ and $\mathbf{V}_{\mathbf{B}}$ are asymptotic due to the previous $\mathbf{A X}++\mathbf{B X}+\mathbf{C X}-$ training, subsequent $A X+$ trials result in a decrement of $V_{A}$ because $V_{A X}\left(=V_{A}+V_{X}\right)$ "overpredicts" the US; that is, $\left(\lambda-V_{A X}\right)<0$. [For this model, $\lambda=$ asymptotic associative strength supportable by the US, and $\Delta \mathbf{V}_{\mathbf{A}}$ $=\left(\lambda-V_{A X}\right)$.] Yet further $B X+$ trials must also result in a decrement in $V_{B}$, by the same mechanism. Assuming that CS-elicited and context-elicited responses are incompatible, the model suggests that the redistribution of associative strengths in 60-60-60 between $A, B, C$, and $X$ then results in such mediocre $V$ values for $A, B$, and $C$ that keypecking cannot be maintained by $V_{A X}, V_{B X}$, or $V_{C X}$. What is pertinent about the Wagner-Rescorla model to the present experiment is that it is the only model of classical conditioning currently available that deals with both acquisition of the response to $B$ in the 30-60-EXT schedule and cessation of the response to $A$ and $B$ in the 60-60-60 schedule. Application of other recent models, such as the "relative waiting time" hypothesis of Jenkins, Barnes, and Barrera (1981) or the
Scalar Expectancy Theory of Gibbon and Balsam (1981), leads to the prediction that the response should cease in 60-60-60, but these models fail to predict the acquisition of keypecking to B (the VT 60-sec component) in the 30-60-EXT training.

It was in view of the ability of the Wagner-Rescorla model to predict acquisition of response to $B$ as well as cessation of response to $A$ and $B$ in 60-60-60 that the present experiment was designed. The model was taken to task: it is crucial to the analysis that the switch from 30-60-EXT (on A, B, and C, respectively) to $60-60-60$ include presentations of key color C. Otherwise, there is no opportunity for $V_{X}$ to increment, because $\mathbf{V}_{\mathbf{X}}$ can increase only in $\mathbf{C X}+$ trials ( $V_{X}$ cannot increase in $\mathrm{AX}+$ or $\mathrm{BX}+$ trials, since $V_{A X}$ and $V_{B X}$ should already be asymptotic). Thus, in 60-60 $(\mathrm{AX}+\mathrm{BX}+)$, although $\mathrm{V}_{\mathrm{AX}}>\lambda$ on $\mathrm{AX}+$ trials, and thus VA should decrease in subsequent BX+ trials, there is no reason to expect any decrement in $V_{B}$. Response to $B$ should be maintained because $V_{B X}$ does not "overpredict" the US; that is, $\left(\lambda-V_{B X}\right)$ is not less than $0 . "$

In the experiment reported here, pigeons were trained first with the multiple VT 30-sec VT 60-sec EXT schedule on key lights A, B, and C. Then they were divided into three matched groups. One group, $\mathrm{ABC}$, was given the kind of nondifferential schedule already described: A, B, and C on VT 60-sec VT 60sec VT 60 -sec. The second group, AB, was given the same overall number and density of reinforcements as the first group, but $\mathrm{C}$ segments were eliminated and replaced with an equal number of $A$ and $B$ segments, both on VT 60-sec. The third group, ABA, was equated with the first group for number of reinforcements and also for number of B segments, and received $A$ and $B$ both on VT $60-s e c$, but there were twice as many $A$ as $B$ segments. Neither Group AB nor Group ABA received any further training with key color $C$. The focus of concern was whether Groups $A B$ and $A B A$ would maintain responding during $B$ segments relative to the decrement in response during B segments expected for Group ABC.

\section{METHOD}

\section{Subjects \\ The subjects were 26 adult homing pigeons that had served as subjects in a variety of experiments with stimuli other than those used here. The animals were maintained at $80 \%$ ad-lib weight in a temperature-controlled colony room that was lighted from 7 a.m. to 8:30 p.m. They had free access to water in their home cage.}

\section{Apparatus}

The animals were trained in three identical, ventilated pigeon compartments, $36 \times 34 \times 30 \mathrm{~cm}(\mathrm{H} \times \mathrm{W} \times \mathrm{L})$, set into larger, lightand sound-attenuating chambers. On one wall of each compartment were two $2.5-\mathrm{cm}$ Plexiglas keys, $25 \mathrm{~cm}$ above the floor, with a distance of $15 \mathrm{~cm}$ between the keys. Only the left key was used. A recessed grain hopper was behind an opening, $5 \times 6 \mathrm{~cm}(\mathrm{H} \times W)$ on the same wall. The feeder was illuminated with a white 7.5-W light for each scheduled 5 -sec reinforcement period. The stimuli used 
were white, red (Kodak Wratten No. 25), green (No. 58), or yellow (No. 8) key lights provided by an Industrial Electronics one-plane projector mounted behind the key. All events were controlled and recorded by a TRS-80 microprocessor (modified) located in an adjacent room.

\section{Procedure}

Although the birds were not naive, they were given three sessions of Pavlovian training in which an $8-\mathrm{sec}$ white key light was followed immediately by $5-\mathrm{sec}$ access to food, independently of response. The interval between each of the 20 key light-food pairings was $60 \mathrm{sec}$.

Immediately following this pretraining, there were nine sessions of 30-60-EXT training (Stage 1). Each session consisted of 72 30sec segments, during which the key was red, green, or yellow, in varying order. Each color was presented once in every block of three segments, with the restriction that no color followed itself. (This restriction was imposed because there was no intertrial interval.) The schedule was multiple VT 30-sec VT 60-sec EXT, with colors assigned to each component balanced over subjects. The key remained illuminated when food was delivered in the presence of any given color, but the segment timer was stopped in order to equate opportunity for response-measurement in each segment.

In Stage 2, the schedule was changed to one in which the likelihood of reinforcement was equal in all segments. Based on their performance in 30-60-EXT, the pigeons were divided into three matched groups. Group ABC $(\mathrm{N}=9)$ received multiple VT 60 -sec VT 60-sec VT 60-sec training with the three key colors used in Stage 1. Group AB $(N=8)$ received multiple VT 60 -sec VT 60 -sec training with key colors $A$ and $B$ only, which were formerly on VT $30-\sec$ (A) and VT 60-sec (B). This group was thus exposed to 36 segments of $A$ and 36 segments of $B$. Group $A B A(N=9)$ also received multiple VT $60-\mathrm{sec}$ VT 60 -sec training, but these animals were exposed to 48 segments with $A$ and 24 segments with $B$. Every time a $\mathrm{C}$ segment was scheduled for an animal in Group $\mathrm{ABC}$, an A segment or a B segment was substituted for an animal in Group AB-the order of A or B was determined randomly-or an A segment was substituted for an animal in Group ABA. This training was continued for eight sessions.

\section{RESULTS}

Figure 1 shows the mean rate of responding to each stimulus in the last five 30-60-EXT training sessions and in the eight 60-60-60 or 60-60 test sessions. The discrimination between key colors A (on VT 30-sec), B (on VT 60-sec), and C (on EXT) in Stage 1 is clear; an analysis of variance showed a highly significant effect of key color $[F(2,50)=29.16, p<.01]$. Responding to $\mathbf{A}$ was greater than responding to $\mathbf{B}$ $[F(1,25)=28.53, \mathrm{p}<.01]$, and responding to $B$ was greater than responding to $C[F(1,25)=11.27, p<$ $.01]$. The overall level of responding appeared to be lower than that reported previously for pigeons in a similar schedule (Brandon, 1981).

All three groups quickly ceased responding to $B$ in Stage 2. Group ABA showed some tendency to suppress faster than the other two groups, as is evident in Figure 1 (right panel), which shows the mean number of responses per minute across the first 24 B segments per session for each group. Differences among the groups were not statistically significant, however, either within the first test session or over all eight test sessions (Fs < 1). There was a significant effect of trials in the first session $[F(23,529)=2.37, p<.01]$,

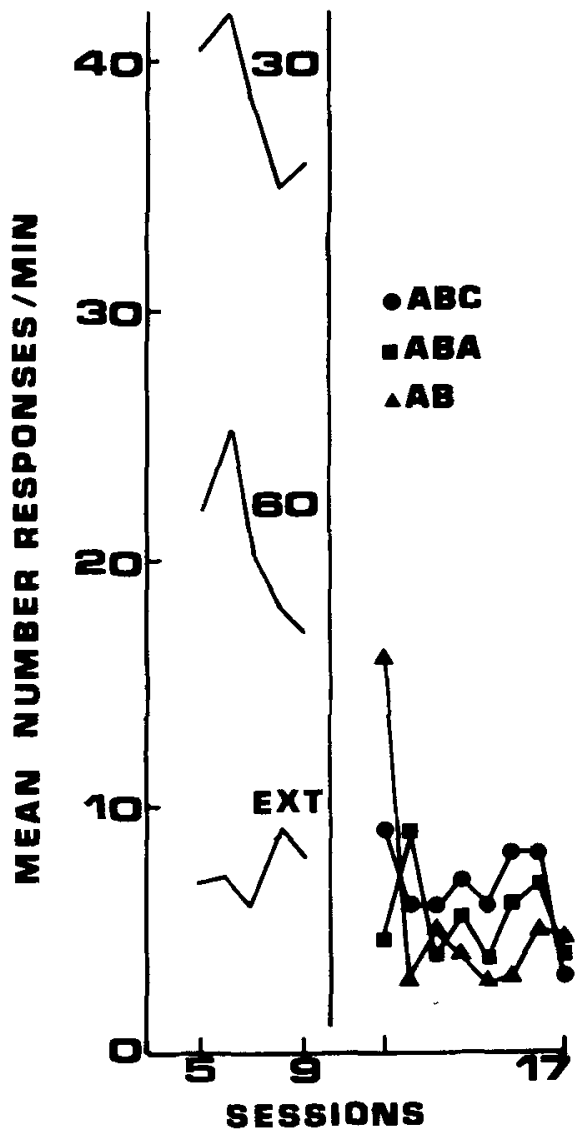

Figure 1. Mean number of responses per minute for all birds to each key stimulus $(A, B$, and $C)$ in the last five sessions of VT 30 sec VT 60-sec EXT training, and to stimulus B for Groups ABC, ABA, and AB in the etght VT 60-sec VT 60-sec VT 60-sec (or VT 60sec FT 60-sec) test sesdions.

but no interaction of trials with groups $(F<1)$. (For Group $\mathrm{AB}$, the first $24 \mathrm{~B}$ segments of each session were used in the analyses.)

\section{DISCUSSION}

One index of a good model is, of course, the extent to which it offers a specific prediction with regard to a specific issue. This was the advantage of the WagnerRescorla model for the problem addressed here. The fact that the model was not supported leaves open the question of what processes determine extinction of keypecking in VT-VT. Scalar Expectancy Theory (SET) successfully predicts equivalent extinction in Groups $A B C, A B A$, and $A B$, but then it is necessary to resort to other models to explain why responding develops to the VT $60-\mathrm{sec}$ stimulus in 30-60-EXT in the first place. Thus, no one model can deal with the pattern of acquisition and extinction reported in the present experiment.

Description of the random CS/US or VT-VT procedure as "nondifferential," "noncontingent," or 
"uncorrelated" is reflected in the notion shared by SET and the Wagner-Rescorla model that there is an interaction between expectancy of reward during the CS and expectancy of reward produced by contextual cues. Perhaps a simpler view of the random or VTVT procedure, that both are situations in which there is no signal for no reward, could lead to a useful alternative description of what conditions are necessary for the acquisition and maintenance of keypecking. If USs are added to intertrial intervals that previously did not contain USs, or VT-VT schedules substituted for VT-EXT schedules, then there is no longer any signal for no reward and keypecking is neither acquired nor maintained (cf. Gamzu \& Schwartz, 1973; Gamzu \& D. R. Williams, 1973). However, if those USs are signaled, then so also are non-US periods, and thus keypecking is both acquired and maintained (Durlach, 1983; Jenkins \& Lambos, 1983), as expected by the Wagner-Rescorla model but not by SET. While SET implies that CS/US contingency is determined within sessions, according to this alternative view the signal for no reward may be present in another session (in the same manner in which the relative waiting time hypothesis of Jenkins et al., 1981, does not specify that the location of long waits in relation to autoshaping trials is critical). In fact, if pigeons are trained with four key colors, A, B, C, and D, so that A and B represent components of a VT-EXT schedule in one session (A on VT, $B$ on EXT) and $C$ and D represent the components of a VT-VT schedule in sessions on interpolated days, responding to $C$ and $D$ is maintained (Brandon, 1981). It should also be noted that the signal for no reward is more effective if it is concurrent with the signal for reward, a behavioral contrast-like effect provided by Jenkins and Lambos (1983) and by Brandon (1981) for the schedule described above: responding to $A$ in $A / B$ sessions was substantially greater than responding to $C$ or $D$ in the $C / D$ sessions. This facilitation effect is reminiscent of behavioral contrast also in its temporal nature: if $\mathrm{C}$ becomes the VT stimulus in VT-EXT sessions (and A is switched to VT-VT sessions), keypecking during C segments increases dramatically within the first half of the session to that level previously shown for $\mathbf{A}$. This approach also permits an integration of an unexpected effect first reported by Lindblom and Jenkins (1981), that if US-omission extinction follows random CS/US training (which itself followed autoshaping), keypecking reemerges. A similar effect has been shown for EXT-EXT following VTVT training (Brandon, 1981). Perhaps the passage of time (in the first EXT-EXT session) becomes a signal that reward no longer is available. This finding fits with the observation that keypecking in such procedures typically reoccurs about halfway through the extinction session (cf. Jenkins \& Lambos, 1983).
If responding in VT segments is facilitated by concurrent EXT segments, and the lack of response in VT-VT is due to the lack of EXT segments, it is necessary to try to describe the processes underlying these effects. One possibility is that, while keypecking during VT segments is likely produced by the contiguity of food and key light (cf. D. R. Williams \& H. Williams, 1969), other behaviors-conditioned to contextual cues, or simply elicited by reinforcement-tend to occur during both the VT and EXT segments. These behaviors consist of a variety of movements produced by the intermittent reinforcement (perhaps such as those suggested by Staddon and Simmelhag, 1971). Such movements are nonreinforced, however, during EXT segments, and then EXT segments serve to differentially extinguish these behaviors (Brandon, 1979). Thus, keypecking in VTEXT suffers less interference than keypecking in VTVT. In this case, of course, cessation of response in the $A B C, A B A$, and $A B$ conditions of the present experiment would be expected: the lack of contingency here represents the lack of extinction exposure. Although this notion could also be used to explain the facilitating effects of longer intertrial intervals (relative to CS intervals) on autoshaping (Gibbon, Baldock, Locurto, Gold, \& Terrace, 1977; Gibbon et al., 1975), there are no data in the present experiment to test such an idea.

\section{REFERENCES}

Ayres, J. J. B., \& DeCosta, M. J. (1971). The truly random control as an extinction procedure. Psychonomic Science, 24, 31-33.

Brandon, S. E. (1979). Key pecking in variable time schedules of reinforcement. Implications for theories of Pavlovian conditioning. Unpublished doctoral dissertation, University of Hawaii.

Brandon, S. E. (1981). Key-light-specific associations and factors determining key pecking in noncontingent schedules. Journal of Experimental Psychology: Animal Behavior Processes, 7, 348-361.

Coulson, G., Coulson, V., \& Gardner, L. (1970). The effect of two extinction procedures after acquisition on a Sidman avoidance contingency. Psychonomic Science, 18, 309-310.

Durlach, P. J. (1983). Effect of signaling intertrial unconditioned stimuli in autoshaping. Journal of Experimental Psychology: Animal Behavior Processes, 9, 374-389.

FARLEY, J. (1980). Automaintenance, contrast, and contingencies: Effects of local vs overall and prior vs impending reinforcement context. Learning and Motivation, 11, 19-48.

Fowlen, H. (1971). Suppression and facilitation by response contingent shock. In F. R. Brush (Ed.), A versive conditioning and learning. New York: Academic Press.

Gamzu, E. R., \& Schwartz, B. (1973). The maintenance of keypecking by stimulus contingent and response independent food presentation. Journal of the Experimental Analysis of Behavior, $19,65-72$.

GamzU, E. R., \& Williams, D. R. (1973). Associative factors underlying the pigeon's key pecking in auto-shaping procedures. Journal of the Experimental Analysis of Behavior, 19, 225-232.

Gibbon, J., BAldock, M. D., Locurto, C. M., Gold, L., \& Terrace, H. S. (1977). Trial and intertrial durations in auto- 
shaping. Journal of Experimental Psychology: Animal Behavior Processes, 3, 264-284.

Gibbon, J., \& Balsam, P. (1981). Spreading association in time. In C. M. Locurto, H. S. Terrace, \& J. Gibbon (Eds.), Autoshaping and conditioning theory. New York: Academic Press.

Gibbon, J., Locurto, C. M., \& Terrace, H. S. (1975). Signalfood contingency and signal frequency in a continuous trials auto-shaping paradigm. Animal Learning Behavior, 3, 317-324.

Jenkins, H. M., BARnes, R. A., \& BARRera, F. J. (1981). Why autoshaping depends on trial spacing. In C. M. Locurto, H. S. Terrace, \& J. Gibbon (Eds.), Autoshaping and conditioning theory. New York: Academic Press.

Jenkins, H. M., \& Lambos, W. A. (1983). Tests of two explanations of response elimination by noncontingent reinforcement. Animal Learning \& Behavior, 11, 302-308.

Kellehen, R. T., Ridple, W. C., \& Cook, L. (1963). Persistent behavior maintained by unavoidable shocks. Journal of the Experimental Analysis of Behavior, 6, 507-517.

Lindblom, L. L., \& Jenkins, H. M. (1981). Responses eliminated by noncontingent or negatively contingent reinforcement recover in extinction. Journal of Experimental Psychology: Animal Behavior Processes, 7, 175-190.

McKenRney, J. W. (1969). Fixed-interval schedules of electric shock presentations: Extinction and recovery of performance under different shock intensities and fixed-interval durations. Journal of the Experimental Analysis of Behavior, 12, 301-313.

Resconla, R. A. (1968). Probability of shock in the presence and absence of CS in fear conditioning. Journal of Comparative and Physiological Psychology, 67, 381-389.

Rescorla, R. A., \& Skucy, J. C. (1969). Effect of responseindependent reinforcers during extinction. Journal of Comparative and Physiological Psychology, 67, 381-389.

Skinner, B. F. (1948). Superstition in the pigeon. Journal of Experimental Psychology, 38, 168-172.

Staddon, J. E. R., \& Simmelhag, V. L. (1971). The "superstition" experiment: A reexamination of its implications for the principle of adaptive behavior. Psychological Review, 78, 3-43.

Stretch, R., Orlotp, E. R., \& Dalhymple, S. D. (1968).
Maintenance of responding by a fixed-interval schedule of shock presentation in squirrel monkeys. Science, 162, 583-585.

Tomis, A. (1981). Effect of unpredictable food on autoshaping. In C. M. Locurto, H. S. Terrace, \& J. Gibbon (Eds.), Autoshaping and conditioning theory. New York: Academic Press.

Tomie, A., Hayden, M., \& Biehl, D. (1980). Effects of response elimination procedures upon subsequent reacquisition of autoshaping. Animal Learning \& Behavior, 8, 237-244.

Tomie, A., Rhon-Stafrond, I., \& Schwam, R. T. (1981). The retarding effect of the TRC response-elimination procedure upon the subsequent reacquisition of autoshaping: Comparison of between- and within-subjects assessment procedures and the evaluation of the role of background contextual stimuli. Animal Learning \& Behavior, 9, 230-238.

UHL, C. N. (1973). Eliminating behavior with omission and extinction after varying amounts of training. Animal Learning \& Behavior, 1, 237-240.

Wagner, A. R. (1969). Stimulus selection and a "modified continuity theory." In G. H. Bower \& J. T. Spence (Eds.), The psychology of learning and motivation (Vol. 3). New York: Academic Press.

W Agner, A. R., \& ResconlA, R. A. (1972). Inhibition in Pavlovian conditioning: Application of a theory. In R. A. Boakes \& M. S. Halliday (Eds.), Inhibition and learning. New York: Academic Press.

Williams, B. A. (1976). Elicited response to signals for reinforcement: The effects of overall versus local changes in reinforcement probability. Journal of the Experimental Analysis of Behavior, 26, 213-220.

Williams, D. R., \& Williams, H. (1969). Automaintenance in the pigeon: Sustained pecking despite contingent non-reinforcement. Journal of the Experimental Analysis of Behavior, 12, 511-520.

ZErLER, M. D. (1968). Fixed and variable schedules of responseindependent reinforcement. Journal of the Experimental Analysis of Behavior, 11, 405-414.

(Manuscript received August 26, 1983; revision accepted for publication January 23, 1984.) 